\title{
Outpatient Management of Acute Diverticulitis. Where is the Border?
}

\author{
Ana Puerta, Angela Santana, Alberto Vilar, Juan Ocaña, Araceli Ballestero and Javier Die Trill* \\ Servicio de Cirugía General y Digestivo, Hospital Univeristario Ramón y Cajal, Spain
}

*Corresponding author: Javier Die Trill, Servicio de Cirugía General y Digestivo, Hospital Univeristario Ramón y Cajal, Madrid, Spain

\begin{tabular}{|c|c|}
\hline ARTICLE INFO & ABSTRACT \\
\hline Received: 幽 February 08, 2021 & $\begin{array}{l}\text { Introduction: The outpatient management of non-complicated acute diverticulitis } \\
\text { has demonstrated its efficacy and safety. The aim of this study is to analyze the failure }\end{array}$ \\
\hline Published: 㓞 February 16, 2021 & $\begin{array}{l}\text { rate of conservative treatment in patients with extraluminal air and/or pericolic abscess, } \\
\text { which clinical relevance is still unknown; and the safety of this treatment in this group }\end{array}$ \\
\hline
\end{tabular}

Angela Santana, Alberto Vilar, Juan Ocaña, Araceli Ballestero, Javier Die Trill. Outpatient Management of Acute Diverticulitis. Where is the Border?. Biomed J Sci \& Tech Res 34(1)-2021. BJSTR. MS.ID.005481.

Materials and Methods: A retrospective analysis of 59 patients with first episode of complicated acute diverticulitis and sigmoid involvement, medically treated on a third level hospital between 2007 and 2018, was made. Failure rate of conservative management, such as need of urgent surgery, was analyzed.

Results: The failure rate was $22 \%$ (13 patients). $18,2 \%$ of the patients with pericolic air as sole finding on the initial CT-scan (grade IA WSES) needed surgical rescue, as well as $14,3 \%$ of the patients with small abscess (grade IB). On the former group failure of medical management was observed in $33,3 \%$ of pelvic abscesses. In the $>4 \mathrm{~cm}$ abscess group (WSES IIA) the failure rate was 33,3\%; $40 \%$ of them requiring percutaneous drainage. The mean time to surgical rescue was 7 days (IQR: 6-19,5 days).

Conclusions: The success of outpatient management depends specially on an adequate patient selection. Based on our experience, and lacking better evidence published on the literature, it should be restricted to patients with no signs of complication such as extraluminal air or abscesses, guarantying our patients' safety.

\section{Introduction}

Colonic diverticulosis is primarily seen in the Western population with prevalence increasing with age. At 40 years of age, approximately $10 \%$ of the Western population has diverticulosis, while this number increases up to $70 \%$ in octogenarians [1-3]. About $15 \%$ of patients will develop acute diverticulitis [3,4]. Of them, $75 \%$ will present with a simple form of acute diverticulitis, but up to $25 \%$ of patients will develop a complication derived from the inflammatory process (intrabdominal abscess, bowel obstruction, fistulae, or intestinal perforation), putting at risk the patient's life $[1,4,5]$. Besides, it is a frequent cause of hospitalization, increasing the healthcare costs significantly $[4,6,7]$. Outpatient management of non-complicated acute diverticulitis has demonstrated its efficacy and safety, becoming a reality in our daily practice [1, 8-15]. Nevertheless, the definition of "non-complicated" seems to be different between research groups.
Most acute diverticulitis classifications are based on the computed tomography (CT) scan findings such as presence of intraabdominal abscess of extraluminal air. The role of the extraluminal air, specially of pericolic localization, or small abscesses is not well stablished on the therapeutic guides, making it necessary to be careful when choosing an outpatient management in some cases. The aim of this study is to analyze the failure rate of conservative treatment in patients presenting with acute diverticulitis associated to extraluminal air and/or pericolic abscess and the safety of this treatment.

\section{Materials and Methods}

A retrospective analysis was made, including 59 patients with first episode of complicated acute diverticulitis and sigmoid involvement, medically treated on a third level hospital between 
2007 and 2018. Complicated acute diverticulitis was defined by the presence of extraluminal air or abscess, regardless of its size of location. The diagnosis was made using CT scan in all cases. The whole sample received an in-hospital treatment, based on intravenous antibiotherapy and parenteral nutrition. Demographic characteristics, acute diverticulitis grade based on the latest World Society of Emergency Surgery classification (WSES guidelines 2016), presence of extraluminal air, abscess (including size and location), in-hospital stay and conservative treatment failure (need of urgent surgery) were reviewed. Patients with a neoplasia underlying the inflammatory process were excluded from the analysis. Statistical analysis was performed using SPSS Statistics ${ }^{\circledR}$ v20 (SPSS, Inc., Chicago, IL). Chi-square and Fisher tests were used to analyze categorical variables. T-Student test was used to compare means for continuous variables with a normal distribution, whereas Wilcoxon test was used for means without normal distribution. Significance was $\mathrm{p}<0,05$.

\section{Results}

The $62,7 \%$ of the patients were women (37 patients) and the median age was 61,5 years (IQR: 47,5-77 years). Eleven cases $(18,6 \%)$ belonged to the IA stage of the WSES classification, given the presence of extraluminal air on CT-scan. 28 patients presented with a small abscess $(\leq 4 \mathrm{~cm})$ associated to the inflammatory process (stage IB) and in 18 cases $(30,5 \%)$ the abscess was bigger than $4 \mathrm{~cm}$ of major diameter (stage IIA). Only in two patients $(3,4 \%)$ distant free gas was observed (stage IIB). The global failure rate of conservative treatment was $22 \%$, with a need of urgent surgical rescue in 13 patients due to development of peritonism or abdominal sepsis. The median age of this subgroup was 53,5 years (IQR: 45-64,5 years), of which 10 patients were women $(76,9 \%)$ and 3 males $(23,1 \%)$. On the subgroup analysis based on WSES classification up to $18,2 \%$ of the patients with pericolic gas as sole finding on CT-scan (stage IA) needed further surgery. The failure rate of conservative treatment was $14,3 \%$ in patients with small abscess (stage IB). Within this group, medical treatment was insufficient in $33,3 \%$ of pelvic abscesses, while the failure rate of pericolic abscess was of $9,1 \%(p=0,1)$. All patients were treated only with antibiotherapy.

On the abscess $>4 \mathrm{~cm}$ group (stage IIA) the failure rate was $33,3 \%$, with no differences between pericolic abscesses or pelvic abscesses ( $30 \%$ vs $37,5 \%$ respectively; $\mathrm{p}=1$ ). Of them, $40 \%$ needed percutaneous drainage. Both patients belonging to the stage IIB group (distant free gas), had a satisfactory response to medical treatment. The median time to surgical rescue was 7 days (IQR: 6-21 days). On the former group the median in-hospital stay was 22 days (IQR: 18 - 33 days) versus 11,5 days on the group of patients who responded to medical management $(p=0,045)$. There was no mortality associated to conservative management.

\section{Discussion}

Non-complicated acute diverticulitis episodes are usually satisfactorily medically managed. Classically, patients were hospitalized to receive intravenous antibiotherapy and fluid therapy. Nevertheless, now a days, there is a tendency to opt for outpatient management, as it has been demonstrated in several randomized controlled trials in patients without major comorbidities [16-22]. In 2014 Biondo et al. [23] published the promising results of the DIVER trial, that demonstrated the efficacy of outpatient treatment of noncomplicated acute diverticulitis and its reduction of sanitary costs. These findings were endorsed by several systematic reviews were a reduction of up to $80 \%$ on sanitary costs was observed, without influencing the results of this kind of therapy [24]. Nevertheless, we should not get carried away by optimism, because the success of this treatment relies on a careful patient selection. Thus, we should be cautious when prescribing an outpatient management for patients with extraluminal air o abscesses. Given the different modifications on the original Hinchey classification, the presence of extraluminal pericolic air or small $(<2-3 \mathrm{~cm})$ pericolic abscesses has been considered as non-complicated acute diverticulitis, being these forms suitable for ambulatory management depending on the authors $[25,26]$.

The clinical relevance of the presence of extraluminal air on the diagnostic CT-scan without peritonism or signs of sepsis remains controversial [1]. Titos-García et al. [27] and Salinnen et al. [28] published their results regarding the medical treatment of patients with pericolic air, obtaining success rates of $90 \%$ and 99\% respectively. In our study, both extraluminal air and pericolic abscess (independently from size) were considered complicated forms of acute diverticulitis, following the classification proposed by WSES on 2016 [29], excluding them from the current outpatient management protocol established in 2016, which has demonstrated to date an efficacy greater that $94 \%$. The decision of maintaining such exclusion criteria is based on the results obtained on the present study. As previously said, we observed that patients with beforehand favorable clinical presentations finally required urgent surgery given the failure of conservative management in a significative percentage of cases. It is noteworthy that 1 out of 5 patients only with extraluminal air or that up to $10 \%$ of small pericolic abscesses needed surgical rescue, which were categories defined as "non-complicated" by some authors. Thus, even if the efficacy and safety of outpatient management of simple acute diverticulitis has been widely demonstrated, as well as its reduction of sanitary costs, it is not a therapeutic regimen that can be universally prescribed, being an adequate patient selection the main success factor. That is why we should be cautious when including on this treatment modality some cases which classification as noncomplicated could be controversial. Main limitations of this study 
are the small simple of patients and its retrospective character. More prospective and randomized studies are needed to establish the best and safest treatment for these patients. Until we have consistent evidence and based on our own experience, given the high failure rates of medical treatment, to preserve our patients security, we recommend limiting outpatient management to cases of simple acute diverticulitis, namely the absence of any sing of complication such as extraluminal air or abscesses, independently from size or location.

\section{References}

1. Bolkenstein HE, van Dijk ST, Consten ECJ, CMA Hoeks, IAM J, et al. (2019) Conservative treatment in Diverticulitis Patients with Pericolic Extraluminal Air and the Role of Antibiotic Treatment. J Gastrointest Surg 23(11): 2269-2276

2. Shahedi K, Fuller G, Bolus R (2013) Long-term risk of acute diverticulitis among patients with incidental diverticulosis found during colonoscopy. Clin Gasteroenterol Hepatol 11(12): 1609-1613.

3. Loffield RJ (2016) Long-term follow-up and development of diverticulitis in patients diagnosed with diverticulosis of the colon. Int J Color Dis 31(1): 15-17.

4. Cirocchi R, Randolph JJ, Binda GA, BM Henry, KA Tomaszewski, et al. (2019) Is the outpatient management of acute diverticulitis safe and effective? A systematic review and meta-analysis. Tech Coloproctol 23(2): 87-100.

5. Tursi A, Papa A, Danese S (2015) Review article: the pathogenesis and medical management of diverticulosis and diverticular disease of the colon. Aliment Pharmacol Ther 42(6):664-684.

6. Shaheen NJ, Hansen RA, Morgan DR, Lisa G, Ringel Y, et al. (2006) The burden of gastrointestinal and liver diseases. Am J Gastroenterol 101(9): 2128-2138.

7. Sandler RS, Everhart JE, Donowitz M (2002) The burden of selected digestive diseases in the United States. Gastroenterology 122(5): 15001511.

8. Jaung R, Kularatna M, Robertson JP, R Vather, David R, et al. (2017) Uncomplicated acute diverticulitis: identifying risk factors for severe outcomes. World J Surg 41(3): 2258-2265.

9. Martín Gil J, Serralta De Colsa D, García Marín A, Alberto VR, Cristina RV, et al. (2009) Safety and efficiency of ambulatory treatment of acute diverticulitis. Gastroenterol Hepatol 32(2): 83-87.

10. Rodríguez-Cerrillo M, Poza-Montoro A, Fernandez-Diaz E (2010) Patients with uncomplicated diverticulitis and comorbidity can be treated at home. Eur J Intern Med 21(6): 553-554.

11. Park HC, Kim BS, Lee BH (2011) Management of right colonic uncomplicated diverticulitis: outpatient versus inpatient management. World J Surg 35(5): 1118-1122.

12. Rueda JC, Jimenez A, Caro A, F Feliu, Jorge E, et al. (2012) Home treatment of uncomplicated acute diverticulitis. Int Surg 97(3): 203-209.

13. Moya P, Arroyo A, Pérez-Legaz J, P Serrano, F Candela, et al. (2012) Applicability, safety and efficiency of outpatient treatment in uncomplicated diverticulitis. Tech Coloproctol 16: 301-307.
14. Rodríguez-Cerrillo M, Poza-Montoro A, Fernandez-Diaz E (2013) Treatment of elderly patients with uncomplicated diverticulitis, even with comorbidity, at home. Eur J Intern Med 24(5): 430-432.

15. Moya P, Bellon M, Arroyo A (2016) Outpatient treatment in uncomplicated acute diverticulitis: 5-year experience. Turk J Gastroenterol 27(4): 330335 .

16. A Mizuki, H Nagata, M Tatemichi, S Kaneda, N Tsukada, et al. (2005) The out-patient management of patients with acute mild-to- moderate colonic diverticulitis, Aliment. Pharmacol Ther 21(7): 889-897.

17. MA Abbas, Rebecca RC, Vicky Y, Raoul B, G Radner, et al. (2013) Triage of patients with acute diverticulitis: are some in-patients candidates for outpatient treatment? Colorectal Dis 15(4): 451-457.

18. S Alonso (2010) Outpatient treatment of patients with uncomplicated acute diverticulitis, Colorectal Dis 12: 278-282.

19. DA Etzioni, Vicky Y, Rebecca RC, Raoul B, Philip IH, et al. (2010) Outpatient treatment of acute diverticulitis: rates and predictors of failure. Dis Colon Rectum 53(6): 861-865.

20. K Friend, AM Mills (2011) Is outpatient oral antibiotic therapy safe and effective for the treatment of acute uncomplicated diverticulitis? Ann Emerg Med 57(6): 600-602.

21. HC Park, BS Kim, BH Lee (2011) Management of right colonic uncomplicated diverticulitis: outpatient versus inpatient management. World J Surg 35(5): 1118-1122.

22. M Rodriguez-Cerrillo (2010) Patients with uncomplicated diverticulitis and comorbidity can be treated at home. Eur J Intern Med 21(6): 553554.

23. S Biondo, G Thomas, K Esther, E Eloy, V Fransesc, et al. (2014) Outpatient versus hospitalization management for uncom- plicated diverticulitis: a prospective, multicenter randomized clinical trial (DIVER Trial). Ann Surg 259(1): 38-44.

24.JD Jackson, T Hammond (2014) Systematic review: outpatient management of acute uncomplicated diverticulitis, Int I Colorectal Dis 29(7): 775-781.

25. Nally DM, Kavanagh DO (2019) Current Controversies in the Management of Diverticulitis: A Review. Dig Surg 36(3): 195-205.

26. Boermeester MA, Humes DJ, Velmahos GC (2016) Contemporary Review of Risk Stratified Management in Acute Uncomplicated and Complicated Diverticulitis. World J Surg 40(10): 2537-2545.

27. Titos-García A, Aranda-Narváez JM, Romacho-López L, Antonio JG, Isaac CS, et al. (2017) Nonoperative management of acute perforated diverticulitis with extraluminal air: results and risk factors for failure. Int J Color Dis 32: 1503-1507.

28. Salinnen VJ, Mentula PJ, Leppaniëmi AK (2014) Nonoperative management in perforated diverticulitis with extraluminal air is safe and effective in selected patients. Dis Colon Rectum 57(7): 875-881.

29. Massimo Sartelli, Fausto Catena, Luca Ansaloni (2016) WSES Guidelines for the management of acute left sided colonic diverticulitis in the emergency setting. World J Emerg Surg 11: 37. 


\section{ISSN: 2574-1241}

DOI: 10.26717/BJSTR.2021.34.005481

Javier Die Trill. Biomed J Sci \& Tech Res

(c) (P) This work is licensed under Creative

Submission Link: https://biomedres.us/submit-manuscript.php

$\begin{array}{ll}\text { BIOMEDICAL } & \text { Assets of Publishing with us } \\ \text { RESEARCHES } & \text { Global archiving of articles } \\ \text { - Immediate, unrestricted online access } \\ \text { - Rigorous Peer Review Process }\end{array}$

